\title{
The Impact of a Conditional Cash Transfer Program on Household Income in Colombia
}

\author{
By Diana Hincapié
}

This paper estimates the impact of Familias en Acción, the largest Colombian conditional cash transfer program, on household income. It uses a Quantile Regression methodology and Difference-inDifference estimators to capture the impact of the program on household income at different quantiles of the income distribution. The estimations show that the program has a positive impact on household income, and that this impact is larger for the households at the lower quantiles of the income distribution. Additional analyses examine whether these results stem from changes in labor market participation or increases in non-labor income. There is some indication that for program participants there was a decrease in labor income, while there was an increase in subsidies or non-labor income. Implications of these findings for conditional cash transfer programs are discussed.

\section{Introduction}

In the last two decades conditional cash transfer (CCT) programs have played an increasingly important role in poverty reduction strategies and social safety net policies in developing countries. These programs provide cash payments to lowincome households that are conditional to behavioral requirements generally related to children's health, nutrition and education. CCTs are expected to contribute to poverty reduction by increasing available household income and consumption in the short term, and by increasing children's human capital, namely education, nutri- tion and health, in the long term. CCTs also work as demand-side complements to the supply of health and education. In this sense, CCT programs are a departure from more traditional approaches of social assistance and an innovative way to provide social services while promoting the accumulation of human capital. CCT programs have been in place since the late 1990 s and early 2000 s and have become increasingly popular, particularly in Latin America. The first large-scale CCT program, PROGRESA (now known as OPORTUNIDADES), was implemented in Mexico in 1997. Since then, these types of programs have expanded to many other Latin American countries, including Brazil, Colombia, Honduras, Bolivia, Ecuador, Chile, Jamaica and Panama. Their popularity and apparent success have also gained notice in some Sub-Saharan African countries (Kakwani et al. 2005), and even New York City, which implemented in 2007 the Opportunity NYC -Family Rewards program (Riccio et al. 2010). In general, impact evaluations of these programs have found some positive effects on educational, nutrition, and health outcomes.

Familias en Acción (FA) is the largest CCT program in Colombia. Launched in 2001, the Colombian government created the program to alleviate the effects of a recession which hit the country in the late 1990s and which caused large losses in welfare, particularly for the lowest-income population (DNP 2008). In 2002, 49.4 percent of the population in the country lived in poverty, while 21.7 percent lived 
in extreme poverty (DNP 2012). Although initially introduced as a safety net to temporarily protect the most vulnerable families from external economic shocks, with time FA also acquired a long-term goal to promote the accumulation of human capital as a means to cease intergenerational poverty transmission (Garcia 2010). Like most CCT programs, the primary purpose of FA is to give cash transfers to low-income households, conditional on their fulfillment of several requirements related to children's education, health and nutrition. The program was initially implemented in 691 of the 1,060 Colombian municipalities existing in 2001. In each municipality, households were eligible to participate in the program if they were classified in Sisbén level 1 as of December $31^{\text {st }}$ of 1999 , and had children between 0 and 17 years old (DNP 2008). The Sisbén is a welfare index used in Colombia to target social programs: the lower the level, the lower the household welfare. The educational subsidy is given to households with children between 7 and 17 years old for each child enrolled in school and who attends 80 percent of classes. In 2008, the CCT value was about $\$ 14,000$ COP (about $\$ 8$ dollars) monthly for each child attending primary school, and about $\$ 28,000$ COP (about $\$ 16$ dollars) monthly for each child attending high school. The health and nutrition component is comprised of a series of required health appointments and educational sessions targeted at mothers and their children between 0 and 6 years old: children must be registered and regularly attend growth and development check-ups and vaccination programs, while mothers have to attend health talks (DNP 2008).

The main impact evaluation of the program found that after five years, the program had a positive impact on: (i) attendance rates for all children's age groups, with the greatest impact on children in high school and for rural children between 14 and 17 years old; (ii) breastfeeding practices, especially in the rural areas; (iii) the frequency of food consumption; and (iv) the nutritional status of children under 7 , especially in the rural areas (DNP 2008, 10-12). Hence, the results of the impact evaluation showed that FA increased the use of social services, but there is very little evidence to date that the program has been effective in achieving its long-term goal of reducing poverty and ending poverty cycles. A recent study that analyzed the long-term effects of FA on human capital found that children who participated in FA were more likely than non-participants to finish high school, particularly girls and beneficiaries in rural areas, while recipients of FA who graduated from high school seem to perform at the same level than similar non-recipient graduates on test scores (Baez and Camacho 2011).

The main impact evaluation of the program used two different econometric methodologies: selection on observables, using linear models and propensity score matching specifications, and Differencein-Differences (DNP 2008). As is very common in impact evaluations of social programs that use regression analyses, the estimations of the impact were based on comparing average outcomes between households in municipalities receiving the program, the treatment group, and households in municipalities not receiving the program, the control group. However, comparing average outcomes might be a problem if one expects the program to have different impacts for different households, for example, with different income levels. In the case of FA, if the lowestincome households among the beneficiaries are more likely to use the program as an opportunity to increase their human capital, it is more likely that the program would help them get out of poverty. On the other hand, if the beneficiaries with relatively more stable incomes use the program only as a short-term remedy for a lack of cash, or if the program creates negative incentives for them to work, they are more likely to remain "trapped" in poverty. In other words, the program may differently impact households at dif- 
ferent points of the income distribution. In this case, it is possible that the different impacts would cancel out and one would find no difference between the average outcomes of the treatment and control households, and mistakenly conclude that the program had no impact at all.

The impact evaluation of FA found that on average household real income increased between 2002 and 2005 for all groups studied, but this increase was greater for the treatment municipalities than for control municipalities. However, when estimating the statistical significance of the impact of the program on household income using the econometric methodologies mentioned above, it did not find a significant effect on average household total income. The only significant difference between the treatment and control groups was found in the household non-labor income in rural areas, but it is difficult to interpret this difference as an impact of the program (DNP 2008). Nevertheless, according to the authors of the impact evaluation:

Even though it is not possible to observe statistically significant impacts of the program on household income, the numbers hinted at a positive effect: total income, including the transfers from the program, is 25.2 percent greater that the income that the household would have without the program; and excluding the transfers it is $\mathbf{2 1 . 2}$ percent ... However, the dispersion in the differences around these averages is too large, and because of that, the observed results are not statistically significant at the usual confidence levels. (DNP 2008) Author's translation.

This means that, given the dispersion in the differences in income between the treatment and control groups around the average, it is possible that the evaluation failed to capture an impact of the program given its focus on average income. To overcome this problem, one can estimate the impact of FA on income at different points of the income distribu- tion to capture the program impact and whether participation in the program unequally affected households with different incomes. In particular, if we care about the long-term effects of the program on poverty reduction, it would be interesting to know how different the impacts for households located at different points of the income distribution may be.

In this context, the central research question of this study is: what is the impact of the Familias en Acción CCT program on mean household income and on income inequality? In other words, what is the program's impact at different parts of the income distribution? The main hypothesis is that the program had a positive impact on household income, and that the impact was greater for those households at the bottom of the income distribution.

The rest of the paper is organized as follows. The second section summarizes the empirical strategy. The third section presents the data sources. The fourth section provides some descriptive statistics. The fifth section presents the results and discussion. Finally, the sixth section offers conclusions and points of further study.

\section{Empirical Strategy}

In order to estimate the impact of the Familias en Acción CCT program at different points of the income distribution, this study uses a Quantile Regression methodology (Koenker and Bassett 1978). The Quantile Regression is a technique in which regressions are estimated for different points of the distribution of the dependent variable, allowing in this case the identification of the impact of the program on household income at different quantiles of the income distribution. Traditional Ordinary Least Squares (OLS) regressions focus on the mean, summarizing the relationship between the dependent variable and a specific regressor: it describes the mean of the dependent variable for each fixed value of the regressor, using a function known as the conditional mean of the response (Hao and Naiman 2007). If used 
in this study, OLS estimates of the impact of the program will measure the impact on average household income. OLS models, also known as conditional mean models, have attractive properties: they can provide a complete and parsimonious description of the relationship between the covariates and the response distribution; and they lead "to estimators (least squares and maximum likelihood) that possess attractive statistical properties, are easy to calculate and are straightforward to interpret" (Hao and Naiman 2007). However, these models also have a very important limitation: they cannot be expanded to non-central locations. Therefore, OLS models are limited in terms of their capacity to estimate these different impacts. This is particularly important in the social sciences, where researchers are interested in social stratification and inequality, which requires examining the properties of a distribution, or particular sections of it. Is it also important in the context of this study, which aims to study the impact of the program at different points of the household income distribution. An alternative to the models described above are conditional-median models, also known as median regression models. According to Hao and Naiman: "the median-regression model can be used to achieve the same goal as a conditionalmean regression modeling: to represent the relationship between the central location of the response and a set of covariates" (2007). However, other quantiles (including the median) can be used to describe different positions of a distribution e.g. quartiles, quintiles, deciles and percentiles. Koenker and Bassett introduced the concept of Quantile Regression, which models conditional quantiles as functions of predictors (1978). That is, instead of specifying the change in the conditional mean of the dependent variable, as OLS does, it specifies the changes in the conditional quantile.

Given the conveniences of using Quantile Regression to understand the response in the conditional quantiles of a distribution as a function of a regressor, this paper uses Quantile Regression to estimate the impact of Familias en Acción on household income at different quantiles of the income distribution. All models are also run using OLS as a point of comparison. Additionally, because the municipalities that participated in the program were not randomly chosen to participate, it is important to consider the possibility that the observed differences in household income between the control and treatment households are simply reflecting pre-existing differences between the two groups, and not the effect of the program (DNP 2008). Therefore a Difference-in-Differences methodology is also used, which allows controlling for unobservable household characteristics, assuming these remain constant over time, and that both the treatment and the control groups react in the same way to macroeconomic effects (DNP 2008). If the control and treatment groups had no systematic differences, a Differencein-difference regression without any controls would properly estimate the impact of the program on the dependent variable of interest - average household income. Such specification is given by:

\section{Model 1:}

$Y_{h}=\alpha+\beta_{1}$ year $+\beta_{2}$ treatment $+\beta_{3}$ year*treatment $+\varepsilon_{h}$

Where $\mathrm{Y}$ is the income variable (in logs, so the coefficients of the regressions can be interpreted as a semi-elasticity), $\mathrm{h}$ represents the household, year is an indicator variable equal to one if the year is 2005, treatment is an indicator variable equal to one if the household is in the treatment group, year*treatment is the interaction between both, and $\varepsilon$ is the error term. The intercept $\alpha$ is the average income of a household in the control group in 2002, $\beta_{1}$ captures changes in all household incomes from 2002 and 2005, and $\beta_{2}$ measures the income effect that is not 
due to the program e.g., some households in the treatment group had larger incomes even before the program started. The coefficient of the interaction, $\beta_{3}$ is the parameter of interest: it measures the impact of the program on household income, assuming that households in the treatment and control group did not increase their income at different rates for other reasons (Wooldridge 2009). $\beta_{3}$ is the Differencein-Difference estimator, which captures the difference between: the difference between the income of households in the treatment and the control groups in 2005 , and the difference between the income of households in the treatment and the control groups in 2002. The Difference-inDifference estimator can be expressed as:

\section{Model 2:}

$\beta_{3}=\left(\right.$ income $_{2005, \text { treat }}-$ income $\left._{2005, \text { cont }}\right)-$
$\left(\right.$ income $_{2002, \text { treat }}-$ income $\left._{2002, \text { cont }}\right)$

Because it is not possible to know if there are systematic differences between the treatment and control groups, the models are run both with and without controls for observable characteristics. The controls included are: age of the head of household, squared age of the head of household, indicator variables for head of household's education level, indicator variables for type of family (married or union with children, married or union without children, single parent with children, single parent without children), and the household dependency ratio (number of household members that do not work with respect to the number of household members that work). The Difference-in-Difference specification with controls is given by:

\section{Model 3:}

$Y_{h}=\alpha+\beta_{1}$ time $+\beta_{2}$ treatment $+\beta_{3}$ time treatment $+\stackrel{2}{X}+\varepsilon_{h}$

Where $\mathrm{X}$ is a vector that includes all control variables.

\section{Data Sources}

This study uses a panel dataset of households from the FA program baseline survey (2002) and the second follow-up survey (2005-2006). The data was collected in 122 Colombian municipalities, from surveys made to 11,462 households during 2002, and 9,566 households in 2005-2006. This study uses socio-demographic data coming from the household surveys, including household income, and administrative data from the program, including specific information from households participating in the program.

The FA program was not a randomized control trial. This means that municipalities, households, and individuals were not randomly selected to participate in the program. Therefore, in order to be able to estimate the impact of the program, data was collected from municipalities receiving the program, "treatment" municipalities, and from municipalities that initially did not participate in the program, "control" municipalities. The latter were chosen to have very similar characteristics to the treatment municipalities: they had all but one characteristic that made them eligible for the program: having a bank.

The dependent variable is total household income. Total household income includes labor income and non-labor income from all members of the family, net transfers to or from other households, the CCT cash transfer for the treatment group, and other subsidies received by the households. The total amounts were calculated on an annual basis, in constant prices of 2005, the year of the second follow-up. Nominal prices of 2002 and 2005 were deflated using the Colombian Consumer Price Index of 2005(CPI).

\section{Descriptive Statistics}

Because municipalities were not randomly selected into the treatment and control groups, it is important to verify if there are systematic differences between these two groups. Table 1 compares five household characteristics for the treatment and control groups. When perform- 
ing a t-test of the differences in means between the characteristics of households in control and treatment municipalities, we cannot reject the null hypothesis that the difference between the means is zero, except for the percent of households married or in union with children. In other words, there is no statistically significant difference between the means of the variables in the households that received the program and those that did not. Even though these means are only descriptive statistics, these data shows that, in principle, the treatment and controls groups are very similar.

Table 2 presents the total household income at the baseline in 2002 and the second follow-up in 2005 for the treatment and control group of households and the percentage change. The table shows that total household real income increased for all households between 2002 and 2005 except for the households in the treatment group in rural areas. The change in real household income was much larger for the treatment households, probably driven by the significant increase in income for treatment group households in urban areas, a 91 percent change. This suggests that, due to the country's economic growth during those years, households in both the treatment and control groups in small municipalities increased their real income, and that the impact might have been larger for treatment municipalities.

Table 3 presents total household income excluding the CCT. This table also shows that there was an increase in real income between 2002 and 2005, both for the treatment and control groups, and that this increase was greater for treatment households. There was a decrease in income for the rural households in the

Table 1: Means for household characteristics for treatment and control groups.

\begin{tabular}{|l|l|l|l|}
\cline { 2 - 4 } \multicolumn{1}{c|}{} & Treatment & \multicolumn{1}{|c|}{ Control } & T-Stat for difference \\
\hline Head's Age & 44.77 & 44.97 & 0.69 \\
\hline Dependency ratio & 0.67 & 0.67 & -0.23 \\
\hline $\begin{array}{l}\text { Percentage of heads with no } \\
\text { education }\end{array}$ & 0.26 & 0.25 & -0.67 \\
\hline $\begin{array}{l}\text { Percentage of married / } \\
\text { union with children }\end{array}$ & 0.79 & 0.82 & $4.35^{*}$ \\
\hline Annual Income (pesos) & $2,735,144$ & $3,622,118$ & 1.6 \\
\hline Note: Author's calculations. * Indicates statistical significance. \\
\hline
\end{tabular}

Table 2: Total household income, Baseline and Follow-up (annual CO pesos, constant prices 2005).

\begin{tabular}{|c|c|c|c|c|}
\hline & & 2002 & 2005 & Difference \\
\hline \multicolumn{2}{|l|}{ Control } & $3,622,118$ & $4,467,931$ & $23.35 \%$ \\
\hline \multicolumn{2}{|l|}{ Treatment } & $3,011,268$ & $4,273,098$ & $41.90 \%$ \\
\hline \multirow[t]{2}{*}{ Rural } & Control & $2,680,068$ & $2,907,411$ & $8.48 \%$ \\
\hline & Treatment & $2,773,235$ & $2,769,959$ & $-0.12 \%$ \\
\hline \multirow[t]{2}{*}{ Urban } & Control & $4,267,341$ & $5,419,003$ & $26.99 \%$ \\
\hline & Treatment & $3,346,750$ & $6,392,155$ & $91.00 \%$ \\
\hline
\end{tabular}


12 The Impact of a Conditional Cash Transfer Program on Household Income in Colombia

Table 3: Total household income excluding CCT,

Baseline and Follow-up (annual CO pesos, constant prices 2005).

\begin{tabular}{|c|l|l|l|l|}
\cline { 3 - 5 } \multicolumn{2}{l|}{} & \multicolumn{1}{c|}{2002} & \multicolumn{1}{c|}{2005} & \multicolumn{1}{c|}{ Difference } \\
\hline \multicolumn{2}{|l|}{ Control } & $3,622,118$ & $4,464,136$ & $23.25 \%$ \\
\hline \multirow{2}{*}{ Treatment } & $2,735,114$ & $3,799,463$ & $38.91 \%$ \\
\hline \multirow{2}{*}{ Rural } & Control & $2,680,068$ & $2,903,675$ & $8.34 \%$ \\
\cline { 2 - 5 } & Treatment & $2,467,746$ & $2,274,861$ & $-7.82 \%$ \\
\hline & Control & $4,267,341$ & $5,415,171$ & $26.90 \%$ \\
\cline { 2 - 5 } & Treatment & $3,112,012$ & $5,948,777$ & $91.16 \%$ \\
\hline
\end{tabular}

Note: Author's calculations.

Table 4: Total household labor income, Baseline and Follow-up (annnual CO pesos, constant prices 2005).

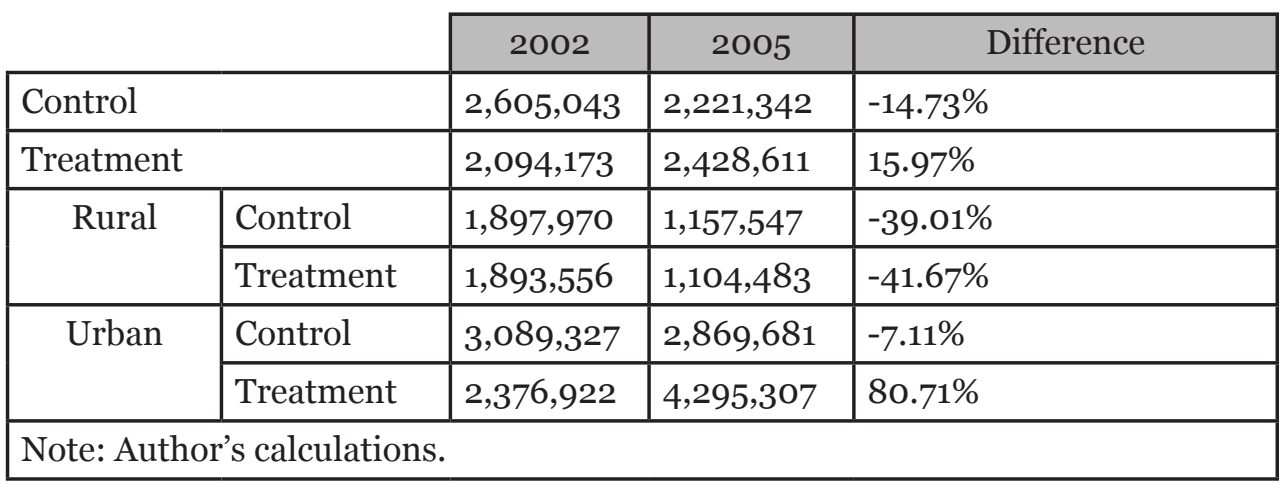

treatment municipalities as well. However, other factors could be driving these results, so they should not be understood as negative impacts of the program. For example, rural areas are more vulnerable to external economic shocks, or to seasonal changes in employment rates.

Because the program could generate different incentives to work, another variable of interest is total household labor income, which includes labor income from all members of the household. If FA created negative incentives to work, households could actually reduce their total labor income, either by having fewer members work, or by reducing the numbers of hours of work being done by household members. Table 4 shows that while total household labor income increased in the treatment households between 2002 and 2005, it went down for households in the control group. Table 5 reports the total household non-labor income excluding the CCT in 2002 and 2005. This non-labor income includes other subsidies that the households receive and household net transfers (transfers to the household from relatives or friends outside the household minus transfers from the household to relatives and friends outside the household). Total household non-labor income significantly increased in both control and treatment municipalities. Finally, Table 6 presents the total annual CCT amount the household received. This is calculated as an average of all payments the household received (payments reported in the survey for treatment households, then multi- 
plied by six to reflect that payments were made every two months). The table shows that there was an increase in the CCT amount for treated households, both in rural and urban areas, and that the increase was much larger in urban areas.

Two factors limit the study's ability to calculate the CCT payments for the treatment and control households: first, some treatment municipalities started receiving the CCT even before the baseline survey, and some control municipalities started receiving CCT before or in 2005 (i.e. they became treatment municipalities); second, there is quite a bit of variation around each household's total annual CCT due to changes in eligibility and distribution mechanisms. These factors in turn limit the study's ability to accurately estimate the dependent variable of total household income, which is calculated by adding CCT to other household incomes.
To address the first issue, this study compares the initial treatment and control households (Intent-to-Treat), ignoring their change of status, and assumes that the control households at the baseline (2002) were also control households at the follow-up. Because of this any CCT for these households is omitted from the calculation of the total household income. With respect to the second issue, it is very difficult to establish the total annual CCT each household received. For example, in the follow-up survey, respondents were asked to report and show the receipt from their last payment, but it is not possible to know how many of these payments the household received during a year. Additionally, some municipalities delayed payments, so some households may have received less money than expected each month. The amount of the CCT received by a household could change if, for ex-

Table 5: Total household non-labor income excluding CCT, Baseline and Follow-up (annual CO pesos, constant prices 2005).

\begin{tabular}{|c|c|c|c|c|}
\hline & & \\
\hline & & 2002 & 2005 & Difference \\
\hline \multicolumn{2}{|l|}{ Control } & $1,017,075$ & $2,242,794$ & $120.51 \%$ \\
\hline \multicolumn{2}{|l|}{ Treatment } & 640,970 & $1,370,851$ & $113.87 \%$ \\
\hline \multirow[t]{2}{*}{ Rural } & Control & 782,098 & $1,746,129$ & $123.26 \%$ \\
\hline & Treatment & 574,190 & $1,170,378$ & $103.83 \%$ \\
\hline \multirow[t]{2}{*}{ Urban } & Control & $1,178,014$ & $2,545,491$ & $116.08 \%$ \\
\hline & Treatment & 735,090 & $1,653,470$ & $124.93 \%$ \\
\hline
\end{tabular}

Table 6: Total household CCT amount, Baseline and Follow-up (annual CO pesos, constant prices 2005).

\begin{tabular}{|l|l|l|l|}
\cline { 2 - 4 } \multicolumn{1}{c|}{} & \multicolumn{1}{c|}{2002} & \multicolumn{1}{c|}{2005} & \multicolumn{1}{c|}{ Difference } \\
\hline Treatment & 231,678 & 473,636 & $104.44 \%$ \\
\hline Rural & 256,316 & 495,099 & $93.16 \%$ \\
\hline Urban & 196,954 & 443,378 & $125.12 \%$ \\
\hline $\begin{array}{l}\text { Note: Author's calculations. The total CCT amount per year } \\
\text { was calculated by estimating the average of the payments } \\
\text { received per household, and multiplying it by 6, as the pay- } \\
\text { ments were bi-monthly. }\end{array}$
\end{tabular}


ample, children first attending elementary grades start attending high school, as the payments are a little bit larger for children in high school. Additionally, some households could have lost their CCT benefits in the middle of a year if they had not followed the program's conditions. Because the dataset does not contain information about the exact amount that the household received in a year, the average household CCT payments received are the next best available alternative data.

The descriptive results presented above suggest that there were significant changes in the household income, and that the increase in income was larger for households in treatment municipalities. However, so far this has only described the differences between the treatment and control groups, before and after the program, which could be reflective of changes in the Colombian economy, other concurrent historic changes, or pre-existing differences between the treatment and control groups.

\section{Results}

Table 7 presents the OLS and Quantile Regression estimates of model (1), that is, a model without any controls, using total household income as the dependent variable. The OLS regression results show that there is a statistically significant impact of the program on household income: participating in the program increases average household total income by 29 percent. This is consistent with the main impact evaluation of the program, which found that total household income for households in FA is 25.2 percent larger than the household would have without the program (DNP 2008). However, in contrast to this study, the earlier evaluation's impact was not statistically significant, probably because of differences in the measurement of the income-related variables and aggregate modeling strategy. The Quantile Regression model presents a better picture than the OLS, as it shows that the estimates at low quantiles are substantially higher. The program has a much greater impact at the lower quantiles of the income distribution. For example, the program increases the conditional income by 83 percent for those households at the 0.15 bottom quantile of the income distribution, and by 54 percent at the 0.25 quantile of the distribution. However, the Quantile Regression shows that the program did not

Table 7: OLS and Quantile Regression estimates of the effect of Familias en Acción on total household income.

\begin{tabular}{lllllll} 
& & \multicolumn{5}{c}{ Quantile } \\
YLS & 0.15 & 0.25 & 0.50 & 0.75 & 0.85 \\
\multirow{2}{*}{ Treatment } & $-0.290^{* * *}$ & $-0.561^{* * *}$ & $-0.530^{* * *}$ & $-0.245^{* * *}$ & $-0.003^{* *}$ & $-0.037^{* * *}$ \\
& $(0.073)$ & $(0.118)$ & $(0.077)$ & $(0.038)$ & $(0.025)$ & $(0.031)$ \\
Year* Treatment & 0.032 & $0.367^{* * *}$ & 0.057 & -0.040 & -0.043 & -0.100 \\
& $(0.052)$ & $(0.107)$ & $(0.066)$ & $(0.036)$ & $(0.019)$ & $(0.028)$ \\
& $0.298^{* * *}$ & $0.830^{* * *}$ & $0.539^{* * *}$ & 0.022 & $-0.059^{*}$ & 0.038 \\
& $(0.079)$ & $(0.131)$ & $(0.086)$ & $(0.047)$ & $(0.034)$ & $(0.038)$
\end{tabular}

Note: This table reports OLS and Quantile Regression estimates of the effect of Familias en Acción on total household income. Dependent variable is in logs, therefore coefficients are interpreted as a semi-elasticity. Standard errors reported in parenthesis. ${ }^{*}$ indicates significance at the $10 \%$ level, ${ }^{* *}$ indicates significance at the $5 \%$ level and ${ }^{* * *}$ indicates significance at the $1 \%$ level. 
Figure 1: OLS and Quantile Regressions coefficients.
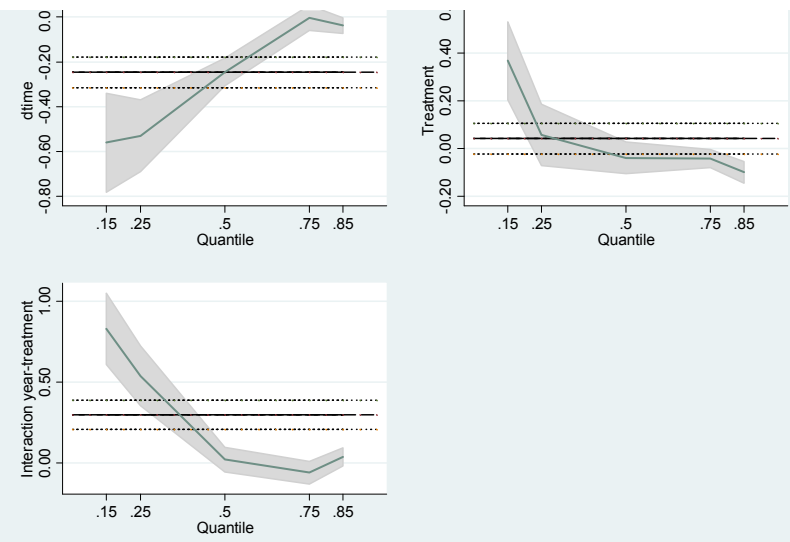

Note: This figure shows OLS and Quantile Regression coefficients and confidence intervals for each regressor as the quantiles vary from 0.15 to 0.85 .

have any statistically significant effect on the median income, or on the higher quantiles of the income distribution.

Figure 1 plots in each graph the OLS and Quantile Regression coefficients for each regressor in this model: dummy variable for year, dummy variable for the treatment, and the interaction variable. The horizontal lines in each graph are the OLS point estimates and confidence intervals, which do not vary with the quantile. The shaded parts are the Quantile Regression estimates and their confidence intervals. The top left graph plots the coefficients on the year variable, showing that it is negative for the whole range of quantiles (0.15 to 0.85), and it is smaller for the lower quantiles. The top right graph plots the coefficients for the treatment variable, showing that the effect of being in the treatment group is larger for the lower quantiles of the income distribution. The lower graph plots the parameter of interest: the coefficients on the year-treatment interaction term. It shows that the impact of the program is positive for the lower quantiles, and negative for the higher quantiles of the income distribution. The results for the models speci- fied by Equation (3) (with controls), are presented below. Table 8 shows the main results of interest for this study: it reports the OLS and Quantile Regression estimates for the impact of FA on total household income including controls for household characteristics. The parameter of interest is the coefficient of year*treatment, which corresponds to the Difference-in-Difference estimator. The controls included are head of household's age, squared head of household's age, indicator variables for head of household's education, indicator variables for type of household, and the household dependency ratio. The omitted or comparison variables are: an indicator variable for heads of household with no education, and an indicator variable for single parent households without any children. In the OLS regression, the head of household's age is not statistically significant. However, the Quantile Regression finds that one more year of age for the head of household is associated with a small but statistically significant increase in income, but only for the 0.75 and 0.85 quantiles of the income distribution. For example, increasing the head of household's age by one year is associated with a 1.8 per- 
Table 8: Quantile Regression and OLS Estimates with controls Dependent variable: Total household income.

\begin{tabular}{|c|c|c|c|c|c|c|}
\hline & & & & Quantile & & \\
\hline & OLS & 0.15 & 0.25 & 0.50 & 0.75 & 0.85 \\
\hline Year & $-0.341^{* * *}$ & $-0.674^{* * *}$ & $-0.581^{* * *}$ & $-0.257^{* * *}$ & $-0.056^{*}$ & -0.036 \\
\hline & $(0.076)$ & $(0.132)$ & (o.083) & (0.044) & (0.034) & (o.035) \\
\hline Treatment & 0.057 & $0.356^{* * *}$ & 0.075 & -0.014 & $-0.045^{*}$ & $-0.071^{* *}$ \\
\hline & (0.054) & (0.114) & (0.068) & (0.035) & $(0.024)$ & (0.028) \\
\hline Year*Treatment & $0.315^{* * *}$ & $0.902^{* * *}$ & $0.535^{* * *}$ & -0.017 & -0.029 & 0.021 \\
\hline & (0.083) & (0.141) & (0.091) & (0.054) & (0.041) & (0.040) \\
\hline Head's age & -0.001 & -0.015 & -0.003 & 0.003 & $0.013^{* * *}$ & $0.018^{* * *}$ \\
\hline & (0.008) & (0.012) & (0.011) & 0.006 & 0.004 & 0.004 \\
\hline Completed & $0.555^{* * *}$ & $0.391^{* * *}$ & $0.513^{* * *}$ & $0.371^{* * *}$ & $0.398^{* * *}$ & $0.349^{* * *}$ \\
\hline & $(0.127)$ & $(0.142)$ & $(0.127)$ & $(0.065)$ & (0.055) & $(0.045)$ \\
\hline Technical & 0.481 & $0.671^{*}$ & 0.415 & 0.426 & $0.415^{* *}$ & $0.489^{* *}$ \\
\hline & $(0.367)$ & (0.350) & $(0.263)$ & $(0.287)$ & $(0.163)$ & (0.198) \\
\hline Completed & 0.983 & 0.395 & $1,326.00$ & $1.525^{* * *}$ & $1.310^{* * *}$ & $1.570^{* * *}$ \\
\hline & (0.733) & (1.172) & $(0.952)$ & (o.350) & (0.294) & $(0.277)$ \\
\hline Married/Union & $0.487^{* * *}$ & 0.472 & 0.354 & $0.409^{* * *}$ & $0.390^{* * *}$ & $0.371^{* * *}$ \\
\hline & $(0.144)$ & $(0.296)$ & $(0.233)$ & (o.132) & (0.092) & $(0.125)$ \\
\hline Married/Union & -0.198 & -0.034 & -0.170 & -0.246 & -0.086 & -0.072 \\
\hline & $(0.183)$ & $(0.371)$ & $(0.275)$ & (0.194) & $(0.143)$ & $(0.161)$ \\
\hline Single parent & $0.534^{* * *}$ & $0.560^{*}$ & $0.493^{* *}$ & $0.392^{* * *}$ & $0.332^{* * *}$ & $0.312^{* *}$ \\
\hline & $(0.146)$ & $(0.304)$ & $(0.238)$ & (o.135) & (0.090) & $(0.124)$ \\
\hline Dependency & -0.008 & -0.002 & 0.013 & -0.000 & 0.010 & $-0.028^{* *}$ \\
\hline & (0.021) & $(0.032)$ & $(0.026)$ & (0.014) & (0.012) & (0.012) \\
\hline
\end{tabular}

Note: This table reports OLS and Quantile Regression estimates of the effect of Familias en Acción on total household income. Dependent variable is in logs, therefore coefficients are interpreted as a semielasticity. Standard errors reported in parenthesis. The omitted variables are: No education, and single parent families without children. Other variables included as controls, but omitted for space reasons are: Squared head's age, and dummies for heads with only elementary education, incomplete high school, incomplete university or graduate studies. * indicates significance at the $10 \%$ level, ${ }^{* *}$ indicates significance at the $5 \%$ level and $* *$ indicates significance at the $1 \%$ level. 
cent change in the total household income at the 0.85 quantile of the distribution. Having a head of household who has completed high school is statistically significant for both the OLS and Quantile Regression models. According to the OLS model, this means that completing high school is associated with a 55 percent increase in the mean household income, with respect to those households whose heads have no education. The results for the Quantile Regression also show that having a head of household who has completed high school is associated in a statistically significant way with household income. The estimated coefficient is very similar for the 0.25 quantile of the income distribution, but the coefficients are lower for other quantiles of the distribution. For example, having a head of household who has completed high school changes total household income by 35 percent to 40 percent at the $0.15,0.5$, 0.75 and 0.85 quantiles of the distribution. The Quantile Regression also shows that there is a substantially large effect of having a head of household who has completed university, but only for the higher quantiles of the income distribution. For example, for the median or 0.5 quantile, this is associated with an increase of more than 100 percent with respect to heads of households with no education.

With regards to family type, there is a clear significant effect of having children on household income, as both the married/unions and the single parent families with children have significantly higher total household income with respect to single parent households with no children. This could be expected, as these are lowincome households, were children usually work or perceive some type of income, and therefore having children increases total household income. The Quantile Regression model shows that a household of either of these two types is significantly associated with higher incomes, particularly at high quantiles of the income distribution. However, for the single parent household with children, the estimates at low quantiles are higher. For example, a single parent household with children is associated with a 56 percent increase in total household income at the 0.15 quantile, while it associated with a 31 percent

Table 9: Quantile Regression and OLS Estimates with controls

Dependent variable: Total household income without the CCT.

\begin{tabular}{lllllll} 
& & \multicolumn{5}{c}{ Quantile } \\
YLS & 0.15 & 0.25 & 0.50 & 0.75 & 0.85 \\
\multirow{2}{*}{ Treatment } & $-0.345^{* * *}$ & $-0.630^{* * *}$ & $-0.602^{* * *}$ & $-0.253^{* * *}$ & $-0.064^{* *}$ & $-0.041^{* * *}$ \\
& $(0.076)$ & $(0.118)$ & $(0.099)$ & $(0.046)$ & $(0.030)$ & $(0.031)$ \\
Year*Treatment & $0.174^{* * *}$ & $-0.373^{* * *}$ & $-0.149^{*}$ & -0.045 & $-0.093^{* * *}$ & -0.130 \\
& $(0.058)$ & $(0.110)$ & $(0.082)$ & $(0.029)$ & $(0.021)$ & $(0.027)$ \\
Controls & O.110 & $0.463^{* * *}$ & 0.075 & $-0.152^{* * *}$ & -0.039 & 0.028 \\
& $(0.088)$ & $(0.149)$ & $(0.128)$ & $(0.055)$ & $(0.041)$ & $(0.041)$ \\
& YES & YES & YES & YES & YES & YES
\end{tabular}

Note: This table reports OLS and Quantile Regression estimates of the effect of Familias en Acción on total household income. Dependent variable is in logs, therefore coefficients are interpreted as a semi-elasticity. Standard errors reported in parenthesis. All regression include controls for head's age, head's education, type of family, and the household dependency ratio. ${ }^{*}$ indicates significance at the $10 \%$ level, ${ }^{* *}$ indicates significance at the $5 \%$ level and ${ }^{* * *}$ indicates significance at the $1 \%$ level. 
increase in total household income at the o.85 quantile of the income distribution.

The parameter of interest, the Difference-in-Difference estimator from the interaction term, shows some interesting results. In the OLS model, year*treatment is statistically significant at the 1 percent level, showing that participating in the program increases total household income by 31 percent.

There is a lot of dispersion in the household income, so the Quantile Regression does a better job in capturing this dispersion. In fact, this model shows that the program's impacts are concentrated at the lower part of the income distribution. For the median household income and the quantiles above 0.5 , the effect of the program is not statistically significant, while the program increases total household income by 90 percent for the 0.15 quantile of income distribution, and 53 for the 0.25 quantile.

\section{Discussion}

In theory, household income should increase as a result of the program's CCT unless there are some unex- pected results. For example, the program could reduce the household members' incentives to work, decreasing their income generation. The program could also reduce net transfers to the household, either because there is a decrease in gross transfers from relatives who do not live in the household, or an increase in the household transfers to relatives outside the household (DNP, 2008). Therefore, it is important to discuss the impact of the program on other variables that can capture these possible results: total household income excluding the CCT, total household labor income, and total household non-labor income excluding the CCT. Table 9 presents the OLS and Quantile Regression estimates for a model that uses specification (3) (with controls), using total household income without the CCT as the dependent variable. The results for models using this dependent variable are important because if a household responded to the program in unexpected ways, such as working less or transferring more money to relatives, the program should impact this dependent variable. The OLS regression does not find a signifi-

Table 1o: Quantile Regression and OLS Estimates with controls Dependent variable: Total household labor income.

\begin{tabular}{lllllll} 
& & \multicolumn{5}{c}{ Quantile } \\
YLS & 0.15 & 0.25 & 0.50 & 0.75 & 0.85 \\
\multirow{2}{*}{ Treatment } & -0.041 & 0.058 & $0.091^{*}$ & $0.102^{* * *}$ & $0.084^{* * *}$ & $0.123^{* * *}$ \\
& $(0.047)$ & $(0.057)$ & $(0.047)$ & $(0.033)$ & $(0.025)$ & $(0.036)$ \\
Year*Treatment & $-0.160^{* * *}$ & 0.030 & -0.000 & $-0.068^{* *}$ & $-0.080^{* * *}$ & $-0.092^{* * *}$ \\
& $(0.030)$ & $(0.042)$ & $(0.027)$ & $(0.028)$ & $(0.025)$ & $(0.030)$ \\
Controls & O.047 & $-0.148^{* *}$ & $-0.164^{* * *}$ & -0.062 & -0.030 & -0.055 \\
& $(0.056)$ & $(0.066)$ & $(0.055)$ & $(0.041)$ & $(0.034)$ & $(0.048)$ \\
& YES & YES & YES & YES & YES & YES
\end{tabular}

Note: This table reports OLS and Quantile Regression estimates of the effect of Familias en Acción on total household income. Dependent variable is in logs, therefore coefficients are interpreted as a semi-elasticity. Standard errors reported in parenthesis. All regression include controls for head's age, head's education, type of family, and the household dependency ratio. * indicates significance at the $10 \%$ level, ${ }^{* *}$ indicates significance at the $5 \%$ level and $* *$ indicates significance at the $1 \%$ level. 
cant effect of the program on total household income without the CCT. However, the Quantile Regression captures a statistically significant effect at the 0.15 and 0.5 quantiles of the income distribution. For households at the lowest quantile (0.15) of the income distribution, the program increases total household income without the CCT by 46 percent, and the program increases income by 15 percent for the median income households (o.5 quantile). Additional models were run using total household labor income and total household non-labor income as dependent variables. The estimations are presented respectively in tables 10 and 11 . There are two important results from these models that need to be mentioned here: first, although the OLS regression does not find a significant effect of the program on total household labor income, the Quantile Regression shows that the program has a negative impact on total household labor income for those at the low quantiles of the distribution. For example, the program reduces labor income for households at the 0.15 quintile of the income distribu- tion in 14.8 percent, and in 16.4 percent for those at the 0.25 quintile of the distribution. This suggests that the lowestincome households, i.e. those at the lowest quintiles of the income distribution, may have reacted to the program by reducing their amount of work, either by working fewer hours, or by having a member of the household stop working. The former case is an unexpected negative impact of the program. However, the latter case is not necessarily a negative impact: what could be happening is that the program offered the right incentives to send children to school instead of making them work to bring additional income to the household. Nevertheless, there are some measurement validity issues for the household labor income that limit the strength of this analysis: because the follow-up survey does not include the income from independent workers, this is omitted from the labor income estimation both for 2002 and 2005. The second important result is that both the OLS and Quantile Regression models find a significant effect of the program on total household non-labor in-

Table 11: Quantile Regression and OLS Estimates with controls Dependent variable: Total household non labor income (without FA).

\begin{tabular}{lllllll} 
& & \multicolumn{5}{c}{ Quantile } \\
Year & OLS & 0.15 & 0.25 & 0.50 & 0.75 & 0.85 \\
& $0.228^{* * *}$ & $0.282^{* * *}$ & $0.456^{* * *}$ & $0.491^{* * *}$ & $0.315^{* * *}$ & $0.319^{* * *}$ \\
\multirow{2}{*}{ Treatment } & $(0.087)$ & $(0.083)$ & $(0,066)$ & $(0.058)$ & $(0.050)$ & $(0.051)$ \\
& $-0.288^{* * *}$ & $-0.333^{* * *}$ & $-0.182^{* * *}$ & $-0.133^{* *}$ & $-0.194^{* * *}$ & $-0.118^{* *}$ \\
Year*Treatment & $(0.069)$ & $(0.076)$ & $(0.062)$ & $(0.058)$ & $(0.045)$ & $(0.051)$ \\
& $0.343^{* * *}$ & $0.269^{* *}$ & $0.255^{* *}$ & $0.210^{* *}$ & $0.212^{* * *}$ & 0.090 \\
Controls & $(0.099)$ & $(0.113)$ & $(0.100)$ & $(0.084)$ & $(0.074)$ & $(0.075)$ \\
& YES & YES & YES & YES & YES & YES
\end{tabular}

Note: This table reports OLS and Quantile Regression estimates of the effect of Familias en Acción on total household income. Dependent variable is in logs, therefore coefficients are interpreted as a semi-elasticity. Standard errors reported in parenthesis. All regression include controls for head's age, head's education, type of family, and the household dependency ratio. * indicates significance at the $10 \%$ level, ** indicates significance at the $5 \%$ level and $* * *$ indicates significance at the $1 \%$ level. 
come excluding the CCT. The OLS model estimates that the program increased total household non-labor income by 34 percent. The Quantile Regression found a significant effect of the program at all quantiles of the non-labor income distribution, except for the highest quantile (0.85), and the impact is slightly higher for the low quantiles of income. For example, the program increases total household non-labor income by 27 percent for the 0.15 quantile of the non-labor income distribution, and 21 percent for the median income household and the 0.75 quantile of the distribution. This result is important because it suggests that the household net transfers and/or the subsidies excluding the CCT increased as a result of the program.

\section{Conclusion}

The results presented in this study confirm the initial hypothesis: the program has a positive impact on total household income, and this impact is larger for the households at the lower quantiles of the income distribution. There is also some evidence that for households at the lowest quintiles of the income distribution, the program had a negative impact on labor income, which suggests that these households may have reacted to the program by reducing their amount of work, either by working fewer hours, or by having a member of the household stop working. As for the total household non-labor income without the CCT, there is some evidence that the program had a positive impact at most quantiles of the income distribution, suggesting that the household net transfers and/or the subsidies excluding the CCT may have increased as a result of the program. These results provide strong evidence that the program had different impacts at different points of the income distribution. This study is one of the first to look at the impact of the Familias en Acción program on different types of households by specifically looking at the impact of receiving the program for households at different points of the income distribution. The Quantile Regressions methodology is particularly useful when a researcher is interested in analyzing the impact of a program or policy on an outcome at different points of its distribution. For example, in this case, Quantile Regression is used to look at the impact of Familias en Acción on household income, for households at different points of the income distribution.

Using a Quantile Regressions methodology, this paper finds evidence that the program had a larger impact for households at the bottom of the income distribution, which suggests that CCT programs might have a bigger impact on the poorest population. Therefore, existing CCT programs and new ones created in the future should aim to better target the programs so that they reach this part of the population, where this type of programs seems to have the largest effect. Future studies should aim to strengthen the measurement validity of the dependent variables used in this study, particularly by improving the estimations of the household labor income, and by better accounting for the actual conditional cash transfers made to each household. By improving these measurements, the methodology used in this study would allow researchers to estimate more accurately the impact of the Familias en Acción program on household income for households at different points of the income distribution. 


\section{References}

Abadie, Alberto, Joshua Angrist, and Guido Imbens. 2002. "Instrumental Variables Estimates of the Effect of Subsidized Training on the Quantiles of Trainee Earnings." Econometrica 70: 91-117.

Angrist, Joshua and Jörn-Steffen Pischke. 2009. Mostly Harmless Econometrics: An Empiricist's Companion. Princeton, NJ: Princeton University Press.

Kakwani, Nanak, Fabio Soares, and Hyun Son. 2005. "Conditional Cash Transfers in African Countries.” International Poverty Centre Working Paper No. 9, United Nations Development Programme, Brasilia, Brazil. http://www.ipc-undp.org/ pub/IPCWorkingPaper9.pdf

Baez, Javier and Adriana Camacho. 2011. "Assessing the Long-Term Effects of Conditional Cash Transfers on Human Capital: Evidence from Colombia." Independent Evaluation Group, Public Sector Unit, Policy Research Working Paper No. 5681,The World Bank, Washington, DC. http://elibrary.worldbank. org/content/workingpaper/10.1596/1813-9450-5681

Cameron, A. Colin and Pravin K. Trivedi. 2010. Microeconometrics Using Stata. College Station, TX: Stata Press.

DNP (Departemento Nacional de Planeación). 2012. "Cifras Pobreza Monetaria: Cifras de Porbreza Multidimensional (IPM). Metas PND.” Portal Web Del

Departamento Nacional de Planeación, 2012. Last accessed March 30. http:// www.dnp.gov.co/Programas/Educaci\%C3\%B3nyculturasaludempleoypobre za/SeminarioInternacional/Cifrasdepobreza.aspx

--—. 2008. Programa Familias en Acción: Impactos en capital humano y evalu ación costo-beneficio del programa. Evaluación de Políticas Públicas 6. Bog ota, Colombia: Departamento Nacional de Planeación, Dirección de Evalu ación de Políticas Públicas. http://www.dnp.gov.co/Portals/o/archivos/ documentos/DEPP/Evaluacion_Politicas_Publicas/Serie_Reportes_de_Eval uacion_No_6_Familias\%20en\%20accion.pdf

Fitzenberg, Bernd, Roger Koenker and Jose A.F. Machado. 2001. Economic Applications of Quantile Regression. New York, NY: Physica-Verlag Heidel berg.

García Jaramillo, Sandra. 2010. "La utilidad de las evaluaciones de impacto ¿Qué hemos aprendido de Familias en Acción y qué nos falta por aprender?” Política Publica Hoy 5 (June): 5-7. http://www.dnp.gov.co/LinkClick.aspx?fileticket=oBbAziw FFJo\%3D\&tabid=99

Hao, Lingxin and Daniel Q. Naiman. 2007. Quantile Regression. Thousand Oaks, CA: Sage Publications, Inc .

Kakwai, Nanak, Fabio Soares, and Hyun Son. 2005. "Conditional Cash Transfers in African Countries.” International Poverty Centre Working Paper No. 9, United Nations Development Programme, Brasilia, Brazil. http://www.ipc-undp.org/ pub/IPCWorkingPaper9.pdf

Koenker, Roger. 2005. Quantile Regression. Cambridge, MA: Cambridge University Press.

Koenker, Roger and Kevin Hallock. 2001. “Quantile Regression.” Journal of Economic Perspectives, 15: 143-156.

Koenker, Roger and Gilbert Bassett, Jr. 1978. "Regression Quantiles.” Econometrica, 46(January): 33-50. http://links.jstor.org/sici?sici=00129682\%28197801\%2946\%3A1\%3C33\%3ARQ\%3E2.0.CO\%3B2-J

Riccio, James, Nadine Deshausay, David Greenberg, Cynthia Miller, Zawadi Rucks, and 
Nandita Verma. 2010. Toward Reduced Poverty Across Generations: Early

Findings from New York City's Conditional Cash Transfer Program. New

York, NY: Manpower Demonstration Research Corporation. http://www. mdrc.org/publications/549/full.pdf

Wooldridge, Jeffrey M. 2009. Introductory Econometrics. A Modern Approach.

Mason, OH: South-Western Cengage Learning.

Diana Hincapié is a third year PhD student of Public Policy and Public Administration at The George Washington University. She is focusing on social and education policy. She also works as a Graduate Research Assistant at the George Washington Institute of Public Policy (GWIPP). Before starting the PhD program at GWU, Diana was a Junior Professional Associate for the Poverty and Gender unit of The World Bank, where she developed and managed datasets, performed econometric analysis, wrote background papers for articles and reports, and supported the unit's technical assistance to Latin American countries. Diana has worked as a Research Assistant since 2005, participating in the elaboration of working papers and research projects related to topics including child labor and the nutrition of Colombian children, Total Factor Productivity in Colombia, poverty and inequality in Latin American countries, and crime in Central America. She has also taught courses on introductory economics at Universidad de Los Andes in Bogota, Colombia, and on economics in policy analysis and research methods and applied statistics at The George Washington University.

The author thanks her editors Mara Andersen, Anderson Heiman, Rachel Brody and Joshua Nadas, for their very valuable feedback and constant motivation, and Professor Elizabeth Rigby, for her advice and useful comments. The author also would like to thank Leandro Medina, for giving her constant support and encouragement in this and all aspects of life. Finally, Diana wants to thank her aunt Myriam, whose life was an example and an inspiration. 